\title{
Experiments on the wet solidus and second critical endpoint of carbonated sediment
}

\author{
WEI CHEN ${ }^{1}$ AND GUOLIANG ZHANG ${ }^{2}$ \\ ${ }^{1}$ Institute of oceanology, Chinese academy of sciences \\ ${ }^{2}$ Institute of oceanology, Chinese Academy of Sciences \\ Presenting Author: wochenwei2014@126.com
}

The mobile phases produced by metamorphic devolatilization of the slab include aqueous fluid, hydrous melt and supercritical fluid. Wet solidus defines the boundary of aqueous fluid and hydrous melt, whereas second critical endpoint (SCEP) marks a complete miscibility between them. Previous studies focused on the phase relationships of sediments- $\mathrm{H} 2 \mathrm{O}$ system, however, the effect of carbonate on the solidus and especially the locations of SCEP are poorly known. Here we experimentally determine the wet solidus and SCEP of carbonated sediments based on texture of run products at $2.5-6.0 \mathrm{GPa}$ and $750-1100^{\circ} \mathrm{C}$. Aqueous fluid occurs interstitially between the solid phases below the solidus (Fig.1a), whereas glasses are present above the solidus (Fig.1b). The wet solidus is therefore placed between $750-800^{\circ} \mathrm{C}$ at 2.5 $\mathrm{GPa}$ and between $850-900^{\circ} \mathrm{C}$ at $4.0 \mathrm{GPa}$. Rounded vesicles are present in the glasses at 2.5-4.0 GPa (Fig.1b, c), which was interpreted as coexisting melt and aqueous fluid and below SCEP. In contrast, quenched solutes at $5.0 \mathrm{GPa}$ show homogeneous appearance, which ranges from globular (Fig.1d), feathery (Fig.1e) to melt-like (Fig.1e) with increasing temperature, providing compelling evidence for equilibrium beyond the SCEP. We thus propose the SCEP at $4.5 \mathrm{GPa}$ and close to $950^{\circ} \mathrm{C}$. Comparison of our results with that of previous studies on sediments- $\mathrm{H} 2 \mathrm{O}$ system, addition of carbonate to sediment- $\mathrm{H} 2 \mathrm{O}$ system increases the temperature of wet solidus by $\sim 100^{\circ} \mathrm{C}$ [1] and the pressure of SCEP by $2.0 \mathrm{GPa}$ [2]. Our results suggest that the fluid released from subducting carbonated sediments at typical subarc depths $(80-170 \mathrm{~km}, 2.5-5.0 \mathrm{GPa})$ is often aqueous fluid or hydrous melt rather than supercritical fluid. However, such C-O-H-silicate supercritical fluid is likely involved in the formation of microdiamond from ultrahighpressure metamorphic terranes in orogenic belts, as the pressure required for diamond formation lies above the SCEP.
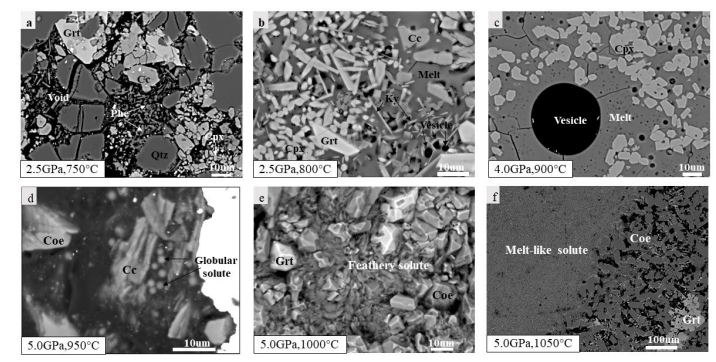